\title{
Predictors of poor glycaemic control in older patients with type 2 diabetes mellitus
}

\author{
Shariff-Ghazali Sazlina ${ }^{1,2}$, MBBS, MMed, Ismail Mastura ${ }^{3}$, MBBS, MMed, Ai Theng $\underline{\text { Cheong }}^{1}$, MBBS, MMed, \\ Adam Bujang Mohamad ${ }^{4}$, BSc, MBA, Haniff Jamaiyah $^{5}$, MD, MCommHealth, Ping Yein Lee ${ }^{1}$, MBBS, MMed, \\ Syed Abdul Rahman Syed Alwi ${ }^{6}$, MBBS, Mmed, Boon How $\underline{\text {Chew}^{1}}$, MD, MMed
}

\begin{abstract}
INTRODUCTION We assessed the predictors of poor glycaemic control among older patients with type 2 diabetes mellitus (T2DM) in Malaysia.

METHODS This cross-sectional study used the data of 21,336 patients aged $\geq 60$ years with T2DM from the Adult Diabetes Control and Management Registry 2008-2009.

RESULTS Predictors of poor glycaemic control were: age groups 60-69 years (odds ratio [OR] 1.96, 95\% confidence interval $[\mathrm{Cl}]$ 1.66-2.33) and 70-79 years (OR 1.43, 95\% Cl 1.20-1.71); Malay (OR 1.53, 95\% Cl 1.41-1.66) and Indian (OR 1.32, 95\% Cl 1.19-1.46) ethnicities; T2DM durations of $5-10$ years (OR $1.46,95 \% \mathrm{Cl} 1.35-1.58$ ) and > 10 years (OR $1.75,95 \% \mathrm{Cl} 1.59-1.91$ ); the use of oral antidiabetic agents only (OR 5.86, 95\% Cl 3.32-10.34), insulin only (OR 17.93, 95\% Cl 9.91-32.43), and oral antidiabetic agents and insulin (OR 29.42, 95\% Cl 16.47-52.53); and elevated blood pressure (OR 1.10, 95\% Cl 1.01-1.20), low-density lipoprotein cholesterol (OR 1.48, 95\% Cl 1.38-1.59) and triglycerides (OR 1.61, 95\% Cl 1.51-1.73). Hypertension (OR 0.71, 95\% Cl 0.64-0.80), hypertension and dyslipidaemia (OR 0.68 , $95 \% \mathrm{Cl} 0.61-0.75$ ), pre-obesity (OR $0.89,95 \% \mathrm{Cl} 0.82-0.98$ ) and obesity (OR $0.76,95 \% \mathrm{Cl} 0.70-0.84$ ) were less likely to be associated with poor glycaemic control.

CONCLUSION Young-old and middle-old age groups (i.e. < 80 years), Malay and Indian ethnicities, longer T2DM duration, the use of pharmacological agents, and elevated blood pressure and lipid levels were associated with poor glycaemic control. The presence of comorbidities, pre-obesity and obesity were less likely to be associated with poor glycaemic control.
\end{abstract}

Keywords: diabetes mellitus, glycaemic control, Malaysia, older patients, registry

\section{INTRODUCTION}

Type 2 diabetes mellitus (T2DM) among older persons is an increasing global health problem in both developed and developing countries, including Malaysia. ${ }^{(1)}$ Changes in lifestyle and a demographic shift toward an ageing population have contributed to the increased prevalence of T2DM in older patients. This causes significant morbidity, disability and mortality, resulting in increased healthcare costs to both the patient and the community. ${ }^{(2,3)}$ It has been predicted that the global cost of diabetes mellitus will increase from USD 376 billion in 2010 to USD 490 billion in 2030. ${ }^{(1)}$

The goal of T2DM management is to delay the onset of complications associated with the disease and impede disease progression; this is achieved mainly through glycaemic control and other cardiovascular disease risk control. ${ }^{(4,5)}$ Unfortunately, glycaemic control remains poor, ranging between $40 \%$ and $60 \%$ worldwide. ${ }^{(6-10)}$ Studies have shown that poor glycaemic control is associated with male gender, ${ }^{(11)}$ Malay and Asian Indian ethnicities, ${ }^{(11,12)}$ the presence of T2DM complications, ${ }^{(11,13)}$ elevated low-density lipoprotein cholesterol (LDL-C) level, ${ }^{(11,13,14)}$ insulin use ${ }^{(14)}$ and non-adherence to medications. ${ }^{(15)}$ However, few studies have focused on T2DM in patients aged $\geq 60$ years. Management of T2DM in older patients differs from that in younger patients, because the former group usually has more comorbidities and disabilities due to age-related changes and an increased susceptibility to hypoglycaemia. ${ }^{(16)}$

The proportion of Malaysians aged $\geq 60$ years is on the rise $\left(6.6 \%\right.$ in 2000 to $7.4 \%$ in 2010). ${ }^{(17)}$ Since longevity is associated with an increased risk of non-communicable diseases such as diabetes mellitus, ${ }^{(18,19)}$ it is not unexpected that the proportion of persons with non-communicable diseases is also on the rise. In a study conducted in 2010, Malaysia was reported to have the tenth highest proportion of people living with diabetes mellitus $(11.6 \%)$, higher than Singapore $(10.2 \%)$, the United Kingdom (3.6\%) and Australia (5.7\%). ${ }^{(20)}$ The prevalence of T2DM among Malaysians aged $>30$ years has increased from $8.2 \%$ in 1996 to $14.9 \%$ in 2006. ${ }^{(21)}$ This prevalence has been shown to increase with age, with the highest proportion recorded among patients aged $60-64$ years (26.1\%). Expenditure on diabetes mellitus accounted for $16 \%$ (USD 600,000) of the Malaysian healthcare expenditure in 2010. ${ }^{(22)}$ The greatest expenditure was among patients aged $\geq 60$ years and this expenditure is projected to increase to USD 1 million by 2030. ${ }^{(22)}$

Glycaemic control among Malaysian adults with T2DM remains poor. The proportion of patients aged $\geq 18$ years with glycosylated haemoglobin (HbA1c) level $\geq 7.0 \%$, in both primary

\footnotetext{
${ }^{1}$ Department of Family Medicine, Faculty of Medicine and Health Sciences, ${ }^{2}$ Institute of Gerontology, Universiti Putra Malaysia, Serdang, Selangor, ${ }^{3}$ Seremban 2 Health Clinic, Seremban, Negeri Sembilan, ${ }^{4}$ Biostatistics Unit, ${ }^{5} \mathrm{C}$ linical Epidemiology Unit, National Clinical Research Centre, Ministry of Health, Kuala Lumpur, ${ }^{6}$ Department of Family Medicine, Faculty of Medicine and Health Sciences, Universiti Malaysia Sarawak, Kuching, Sarawak, Malaysia

Correspondence: Dr Sazlina Shariff-Ghazali, Associate Professor, Department of Family Medicine, Faculty of Medicine and Health Sciences, Universiti Putra Malaysia, 43400, Serdang, Selangor, Malaysia. sazlina@upm.edu.my
} 
and tertiary care centres, was reported to be between $30.9 \%$ and $80.0 \%{ }^{(10,23)}$ Glycaemic control was found to be worse among adults of Malay ethnicity, followed by those of Indian and Chinese ethnicities. ${ }^{(24)}$ The proportion of Malaysians aged $\geq 60$ years with HbA1c level $\geq 7.0 \%$ was $58.3 \%$. ${ }^{(25)}$ Adult Malaysians with poor glycaemic control were found to lack knowledge on diabetes mellitus and demonstrate inadequate self-care practices. ${ }^{(26)}$ There is limited information on the predictors of poor glycaemic control among patients aged $\geq 60$ years with T2DM in Malaysia. Thus, the aim of the present study was to determine the demographic and clinical predictors of poor glycaemic control for the aforementioned subpopulation.

\section{METHODS}

The present cross-sectional study utilised the data of 21,336 Malaysian patients aged $\geq 60$ (range 60-104) years with T2DM. The data was derived from the Adult Diabetes Control and Management (ADCM) Registry 2008-2009;(27) the web-based registry was initiated in May 2007 for patients with diabetes mellitus aged $\geq 18$ years and attending any one of the 303 public primary healthcare clinics and hospitals in Malaysia. The study was approved by the Medical Research and Ethics Committee, Ministry of Health, Malaysia.

In the ADCM Registry, demographic data, the type and duration of diabetes mellitus, treatment modalities (e.g. diet and exercise, oral antidiabetic medications and/or insulin), risk factors (e.g. blood pressure [BP], body mass index [BMI], waist circumference and fasting plasma lipids) and presence of T2DM complications (e.g. retinopathy, coronary heart disease, stroke, nephropathy, diabetic foot problems [including peripheral vascular disease, ulcer, neuropathy and deformity] and erectile dysfunction) are reported and updated as and when changes occur or information becomes available. Results of laboratory assessments and clinical examinations are accepted only if they were performed within 12 months of data collection. Details about the ADCM Registry have been described in other studies. ${ }^{(10,27)}$

In the ADCM Registry and the present study, patients with T2DM were defined as those either with a documented diagnosis of T2DM according to World Health Organization (WHO) criteria or whose current treatment consisted of lifestyle modification, oral antidiabetic agents and/or insulin. ${ }^{(10)}$ Older patients were defined as those aged $\geq 60$ years, as Malaysia uses the United Nations age demarcation to define such demographics in national policies. ${ }^{(28)}$

The outcome measured in the present study was glycaemic control. Poor glycaemic control was defined as HbA1c level $\geq 8.0 \%$, as most of the participants in the present study had comorbidities. ${ }^{(4)}$ The duration of T2DM, presence of comorbidities, treatment modalities used (e.g. antidiabetic agents) and cardiovascular risk factors (BP, BMI, waist circumference and fasting plasma lipids) were evaluated. The target for BP control was set at $<130 / 80 \mathrm{mmHg}$. ${ }^{(29)}$ The categories for BMI were: (a) underweight: < $18.5 \mathrm{~kg} / \mathrm{m}^{2}$; (b) normal: $18.5-22.9 \mathrm{~kg} / \mathrm{m}^{2}$; (c) pre-obese: $23-27.4 \mathrm{~kg} / \mathrm{m}^{2}$; and (d) obese: $\geq 27.5 \mathrm{~kg} / \mathrm{m}^{2}$. ${ }^{(30)}$ The targeted waist circumference was $<90 \mathrm{~cm}$ for men and $<80 \mathrm{~cm}$ for women. The targets for lipid control were: (a) LDL-C:
$<2.6 \mathrm{mmol} / \mathrm{L}$; (b) high-density lipoprotein cholesterol (HDL-C): $>1.0 \mathrm{mmol} / \mathrm{L}$ for men and $>1.3 \mathrm{mmol} / \mathrm{L}$ for women; and (c) triglycerides (TG): < $1.7 \mathrm{mmol} / \mathrm{L}$. ${ }^{(29)}$ If patients had T2DM complications, details about the complications were also recorded. The methods used in the present study are similar to those described in a previous study. ${ }^{(25)}$

Data was analysed using the Statistical Package for the Social Sciences version 18.0 (SPSS Inc, Chicago, IL, USA). Normality was assumed, considering the large dataset, and no imputation for missing data was performed. Missing values for sociodemographic details, clinical profiles and cardiovascular risk factors ranged from $0.2 \%$ to $19.3 \%$. There were also missing values in the T2DM complications category (up to $38.3 \%$, range $3,788-8,173$ ). The participants' characteristics were also studied according to their ethnicities (Malay, Chinese, Indian or indigenous bumiputera). This was done to examine the influence of ethnicity on the demographic and clinical profiles of our study cohort.

To determine the variables associated with poor glycaemic control, the patients' profiles (age, gender, ethnicity, T2DM duration, comorbidities and treatment modalities) and cardiovascular risk factors (BP, BMI, waist circumference, LDL-C, $\mathrm{HDL}-\mathrm{C}$ and TG) were tested for associations with $\mathrm{HbA} 1 \mathrm{c}$ status (a cut-off of $\geq 8.0 \%$ was used). Both univariate and multivariate analyses were applied to assess the determinants of poor glycaemic control. T2DM complications were not included in further analysis because they were the result of the progression of poor glycaemic control.

Data was presented as frequency (percentage), and Pearson's chi-square test was used for statistical significance. Variables that were found to be significant in the univariate analysis were tested using multiple logistic regression analysis with backward likelihood ratio in a stepwise procedure. We included all variables as factors in the logistic regression model to obtain the adjusted odds ratio (OR) for predicting poor glycaemic control. The final models presented were based on the final model selection from the stepwise method. Adjusted ORs with 95\% confidence intervals $(\mathrm{Cls})$ and p-values were reported to determine the strength of contribution of each predictor toward poor glycaemic control. The significance level was set at $p$-value $<0.05$.

\section{RESULTS}

Among the 21,336 patients with T2DM aged $\geq 60$ years, $38.4 \%$ had $\mathrm{HbA} 1 \mathrm{c}$ level $\geq 8.0 \%$. The mean age of the patients was $67.78 \pm 6.26$ (range 60-104) years. Most of the patients were aged $60-69$ years $(65.3 \%)$, female $(57.3 \%)$, Malay $(55.7 \%)$, had a T2DM duration of 5-10 years (39.4\%), had concomitant hypertension and dyslipidaemia (44.8\%), were on oral antidiabetic agents $(85.8 \%)$, and used two antidiabetic agents (55.3\%). Table I summarises the patients' characteristics.

Differences in demographic and clinical factors were observed among the ethnic groups (Table II). There were more Chinese $(7.9 \%)$ than Malay patients $(4.1 \%)$ in the $\geq 80$ years age group. While there were more female than male indigenous bumiputera patients with T2DM, the gender proportions for 
Table I. Characteristics of the study population.

\begin{tabular}{|c|c|}
\hline Characteristic & No. (\%) \\
\hline \multicolumn{2}{|l|}{ Age group $(y r)(n=21,336)$} \\
\hline $60-69$ & $13,943(65.3)$ \\
\hline $70-79$ & $6,264(29.4)$ \\
\hline$\geq 80$ & $1,129(5.3)$ \\
\hline \multicolumn{2}{|l|}{ Gender $(n=21,286)$} \\
\hline Male & $9,081(42.7)$ \\
\hline Female & $12,205(57.3)$ \\
\hline \multicolumn{2}{|l|}{ Ethnicity $(n=21,293)$} \\
\hline Malay & $11,858(55.7)$ \\
\hline Chinese & $5,859(27.5)$ \\
\hline Indian & $3,446(16.2)$ \\
\hline Indigenous bumiputera & $130(0.6)$ \\
\hline \multicolumn{2}{|l|}{ T2DM duration $(y r)(n=21,336)$} \\
\hline$<5$ & $7,965(37.3)$ \\
\hline $5-10$ & $8,403(39.4)$ \\
\hline$>10$ & $4,968(23.3)$ \\
\hline \multicolumn{2}{|l|}{ Comorbidity ( $n=21,336)$} \\
\hline Hypertension & $7,869(36.9)$ \\
\hline Dyslipidaemia & $1,382(6.5)$ \\
\hline Hypertension and dyslipidaemia & $9,561(44.8)$ \\
\hline None & $2,524(11.8)$ \\
\hline \multicolumn{2}{|l|}{ Treatment modality $(n=21,106)$} \\
\hline Diet and exercise & $260(1.2)$ \\
\hline Oral antidiabetic agents only & $18,113(85.8)$ \\
\hline Insulin only & $795(3.8)$ \\
\hline Oral antidiabetic agents and insulin & $1,938(9.2)$ \\
\hline \multicolumn{2}{|c|}{ No. of antidiabetic agent used $(n=19,603)$} \\
\hline 1 & $8,177(41.7)$ \\
\hline 2 & $10,844(55.3)$ \\
\hline$\geq 3$ & $582(3.0)$ \\
\hline
\end{tabular}

the other ethnic groups were almost equal. The proportion of patients who had T2DM for 5-10 years was also similar across the ethnic groups. However, there were fewer Malay patients $(17.5 \%)$ who had a T2DM duration $\geq 10$ years as compared to the other ethnic groups. There was a greater proportion of both hypertension and dyslipidaemia among the Chinese patients as compared to the other ethnic groups. The proportion of patients who received oral antidiabetic agents was almost equal among all the ethnic groups. Fewer Indian patients $(3.1 \%)$ were on insulin as compared to Malay $(3.8 \%)$, Chinese $(4.1 \%)$ and bumiputera (4.6\%) patients. In the present study, $16.3 \%(2,709 / 16,613)$ of the patients had nephropathy, $12.4 \%(1,638 / 13,163)$ had retinopathy, $10.1 \%(1,649 / 16,250)$ had coronary heart disease, $2.5 \%(429 / 17,054)$ had stroke, $6.7 \%(1,175 / 17,548)$ had diabetic foot problems and $26.5 \%$ $(298 / 1,124)$ had erectile dysfunction.

Univariate analysis showed that poor glycaemic control was associated with age $(p<0.001)$, ethnicity $(p<0.001)$, T2DM duration $(p<0.001)$, comorbidities $(p<0.001)$ and treatment modalities $(p<0.001)$ (Table III). In addition, BP $(p=0.021)$, BMI $(p=0.005)$, LDL-C $(p<0.001)$, HDL-C $(p=0.001)$ and TG $(p<0.001)$ were also associated with poor glycaemic control (Table IV).

Table $V$ summarises the predictors of poor glycaemic control in our study population. The following patient characteristics were found to be associated with poor glycaemic control: age 60-69 years (OR 1.96, 95\% Cl 1.66-2.33) and 70-79 years (OR 1.43, 95\% Cl 1.20-1.71); Malay ethnicity (OR 1.53, 95\% Cl 1.41-1.66) and Indian ethnicity (OR 1.32, 95\% Cl 1.19-1.46); T2DM duration of $5-10$ years (OR 1.46, 95\% Cl 1.35-1.58) or $>10$ years (OR 1.75, 95\% Cl 1.59-1.91); use of oral antidiabetic agents only (OR 5.86, 95\% Cl 3.32-10.34), insulin only (OR $17.93,95 \% \mathrm{Cl} 9.91-32.43)$ or oral antidiabetic agents and insulin (OR 29.42, 95\% Cl 16.47-52.53); and elevated BP (OR 1.10, 95\% Cl 1.01-1.20), LDL-C (OR 1.48, 95\% Cl 1.38-1.59) and TG (OR $1.61,95 \% \mathrm{Cl} 1.51-1.73)$. The following patient characteristics were less likely to be associated with poor glycaemic control: hypertension only (OR $0.71,95 \% \mathrm{Cl} 0.64-0.80)$ or hypertension and dyslipidaemia (OR 0.68, 95\% Cl 0.61-0.75); and BMI of 23.0-27.4 (OR 0.89, 95\% Cl 0.82-0.98) or > 27.5 kg/m² (OR $0.76,95 \% \mathrm{Cl} 0.70-0.84)$. No interaction was found between the predictors of poor glycaemic control.

\section{DISCUSSION}

The aim of the present study was to determine the predictors of poor glycaemic control among older patients (i.e. aged $\geq 60$ years) with T2DM. In keeping with other studies, ${ }^{(11,31)}$ we found that being in the young-old and middle-old age groups (i.e. $<80$ years) was a predictor of poor glycaemic control. Both Toh et $\mathrm{al}^{(11)}$ and Helmer et $\mathrm{a}^{(31)}$ reported that older patients aged $<75$ years and $<80$ years, respectively, were significantly more likely to have poor glycaemic control. While the reason for this is unclear, in the present study, it could have been due to the higher proportion of Malays with poor glycaemic control and who were also in the 60-69 years age group as compared to patients from the other ethnic groups. Furthermore, Malays made up the second lowest proportion of patients aged $\geq 80$ years.

In the present study, patients of Malay and Indian ethnicities were associated with poor glycaemic control. This finding is consistent with that of a study conducted in Singapore on adults with T2DM in which Malay and Indian patients were found to have significantly poorer glycaemic control than Chinese patients. ${ }^{(11)}$ A possible reason for this is that Malay and Indian patients may have greater insulin resistance. In a study conducted in Singapore, Khoo et al found that adult T2DM patients of Malay and Indian ethnicities had greater insulin resistance than their Chinese counterparts; this increased insulin resistance was found to be independent of BMI. ${ }^{(32)}$ The Malaysian Adult Nutrition Survey 2003 also reported that the proportion of adult Malays and Indians who engaged in adequate exercise was lower than that of the Chinese and other ethnic groups. ${ }^{(33)}$ In other words, the poor glycaemic control observed may have been due to different lifestyle habits among the ethnic groups. Further studies are required to explore the differences in lifestyle habits of the major ethnic groups in Malaysia. Studies should also be conducted to 
Table II. Demographic and clinical factors according to ethnicity.

\begin{tabular}{|c|c|c|c|c|c|}
\hline \multirow[t]{2}{*}{ Factor } & \multicolumn{4}{|c|}{ No. (\%) } & \multirow[t]{2}{*}{ p-value } \\
\hline & Malay & Chinese & Indian & Indigenous bumiputera & \\
\hline Age group (yr) & & & & & $<0.001^{+}$ \\
\hline $60-69$ & $8,140(68.6)$ & $3,400(58.0)$ & $2,293(66.5)$ & $78(60.0)$ & \\
\hline $70-79$ & $3,232(27.3)$ & $1,999(34.1)$ & 975 (28.3) & $47(36.2)$ & \\
\hline$\geq 80$ & $486(4.1)$ & $460(7.9)$ & $178(5.2)$ & $5(3.8)$ & \\
\hline Gender & & & & & $<0.001^{+}$ \\
\hline Male & 4,926 (41.6) & $2,684(45.9)$ & $1,415(41.1)$ & $51(39.2)$ & \\
\hline Female & $6,925(58.4)$ & $3,163(54.1)$ & $2,026(58.9)$ & $79(60.8)$ & \\
\hline T2DM duration (yr) & & & & & $<0.001^{+}$ \\
\hline$<5$ & $4,885(41.2)$ & $1,997(34.1)$ & $1,037(30.1)$ & $37(28.5)$ & \\
\hline $5-10$ & $4,901(41.3)$ & $2,120(36.2)$ & $1,315(38.2)$ & $52(40.0)$ & \\
\hline$>10$ & $2,072(17.5)$ & $1,742(29.7)$ & $1,094(31.7)$ & $41(31.5)$ & \\
\hline Comorbidity & & & & & $<0.001^{+}$ \\
\hline Hypertension & $4,479(37.8)$ & $2,084(35.6)$ & $1,254(36.4)$ & $43(33.1)$ & \\
\hline Dyslipidaemia & $727(6.1)$ & $344(5.9)$ & $298(8.6)$ & $10(7.7)$ & \\
\hline Hypertension and dyslipidaemia & $5,090(42.9)$ & $2,884(49.2)$ & $1,504(43.6)$ & $56(43.1)$ & \\
\hline None & $1,562(13.2)$ & $547(9.3)$ & $390(11.3)$ & $21(16.2)$ & \\
\hline Treatment modality & & & & & $<0.001^{+}$ \\
\hline Diet and exercise & $124(1.1)$ & $109(2.0)$ & $25(0.7)$ & $2(1.5)$ & \\
\hline Oral antidiabetic agents only & $10,183(86.8)$ & $4,481(83.0)$ & $2,909(85.5)$ & $110(84.6)$ & \\
\hline Insulin only & $444(3.8)$ & $237(4.4)$ & $104(3.1)$ & $6(4.6)$ & \\
\hline Oral antidiabetic agents and insulin & $979(8.3)$ & $573(10.6)$ & $365(10.7)$ & $12(9.2)$ & \\
\hline
\end{tabular}

*Analysis performed using Pearson's chi-square test. †statistically significant. T2DM: type 2 diabetes mellitus

identify the barriers to adopting a healthy lifestyle among these ethnic groups.

A T2DM duration of $\geq 5$ years was associated with poor glycaemic control in the present study. Patients with a longer duration of T2DM were shown to have higher levels of HbA1c. ${ }^{(34)}$ In fact, patients who had T2DM duration of $>10$ years were found to have $15.3 \%$ higher $\mathrm{HbA} 1 \mathrm{c}$ levels than those with shorter durations. ${ }^{(14)}$ Increased T2DM duration is associated with disease progression. Progressive loss of pancreatic beta cell function has been shown to cause poor glycaemic control regardless of treatment regimen. ${ }^{(35)}$ In the present study, the association between a T2DM duration of $\geq 5$ years and poor glycaemic control could have been due to the significantly greater proportion of Indian patients with poor glycaemic control and the fact that most of them had T2DM for $>5$ years.

In the present study, the use of oral antidiabetic agents and/ or insulin was associated with poor glycaemic control. This finding concurs with several studies that found that patients who used insulin only ${ }^{(11,13,14)}$ or in combination with oral antidiabetic medications ${ }^{(34)}$ were more likely to have poor glycaemic control than those treated with lifestyle modifications alone. Most of the patients in the present study were on two or more antidiabetic agents on top of other medications (e.g. antihypertensives, lipid-lowering agents and antiplatelet agents). The need for multiple medications could be confounded by the chronicity and severity of T2DM. ${ }^{(34)}$ Polypharmacy could contribute to an increased risk of side effects and drug-drug interactions, which would deter patient adherence to treatment regimens, resulting in poor glycaemic control. ${ }^{(15,36)}$ However, the relationship between medication adherence and glycaemic control could not be determined in this study, as medication adherence was not assessed.

We found that elevated BP was associated with poor glycaemic control. This finding was consistent with those of another study, in which T2DM patients with uncontrolled hypertension were found to be more likely to have poor glycaemic control than T2DM patients with normal BP. ${ }^{(11)}$ In the present study, a higher proportion of Malay and Indian patients had hypertension, and since patients of these two ethnicities were also found to have poor glycaemic control, this could have, in part, accounted for the association of elevated BP with poor glycaemic control. While older patients have been shown to benefit from BP reduction, it should be noted that they have reduced tolerance; thus, treatment has to be introduced gradually. ${ }^{(4)}$

Congruent with other studies on glycaemic control, ${ }^{(11,13)}$ our study found that high LDL-C level was associated with poor glycaemic control. Adult T2DM patients with an LDL-C level $\geq 2.6 \mathrm{mmol} / \mathrm{L}$ were found to be 1.4 times more likely to have poor glycaemic control. ${ }^{(11)}$ Furthermore, T2DM patients with an LDL-C level $>4.1 \mathrm{mmol} / \mathrm{L}$ were reported to be 4.3 times more likely to have poor glycaemic control than those with an LDL-C level $<2.6 \mathrm{mmol} / \mathrm{L}$. ${ }^{(1)} \mathrm{A}$ study on adult T2DM patients with dyslipidaemia reported that poor lipid control was associated with poor dietary compliance, the use of multiple medications and inappropriate management of dyslipidaemia by the treating physician. ${ }^{(37)}$ Therefore, better management and control of dyslipidaemia is warranted, especially in older patients with T2DM, as their risk for cardiovascular events and mortality is 
Table III. Demographic and clinical factors associated with glycaemic control.

\begin{tabular}{|c|c|c|c|}
\hline \multirow[t]{2}{*}{ Factor } & \multicolumn{2}{|c|}{ No. (\%) } & \multirow[t]{2}{*}{ p-value* } \\
\hline & $\begin{array}{c}\text { HbA1c } \\
\text { level }<8.0\end{array}$ & $\begin{array}{c}\text { HbA1c } \\
\text { level } \geq 8.0\end{array}$ & \\
\hline $\begin{array}{l}\text { Age group (yr) } \\
(n=21,336)\end{array}$ & & & $<0.001^{+}$ \\
\hline $60-69$ & $8,106(61.7)$ & $5,837(71.3)$ & \\
\hline $70-79$ & $4,189(31.9)$ & $2,075(25.3)$ & \\
\hline$\geq 80$ & $851(6.5)$ & $278(3.4)$ & \\
\hline Gender $(n=21,286)$ & & & 0.917 \\
\hline Male & $5,594(42.6)$ & $3,487(42.7)$ & \\
\hline Female & $7,527(57.4)$ & $4,678(57.3)$ & \\
\hline Ethnicity $(n=21,293)$ & & & $<0.001^{+}$ \\
\hline Malay & $6,883(52.4)$ & $4,975(60.9)$ & \\
\hline Chinese & $4,028(30.7)$ & $1,831(22.4)$ & \\
\hline Indian & $2,131(16.2)$ & $1,315(16.1)$ & \\
\hline $\begin{array}{l}\text { Indigenous } \\
\text { bumiputera }\end{array}$ & $84(0.6)$ & $46(0.6)$ & \\
\hline $\begin{array}{l}\text { T2DM duration (yr) } \\
(n=21,336)\end{array}$ & & & $<0.001^{+}$ \\
\hline$<5$ & $5,534(42.1)$ & $2,431(29.7)$ & \\
\hline $5-10$ & $4,933(37.5)$ & $3,470(42.4)$ & \\
\hline$>10$ & $2,679(20.4)$ & $2,289(27.9)$ & \\
\hline $\begin{array}{l}\text { Comorbidity } \\
(n=21,336)\end{array}$ & & & $<0.001^{+}$ \\
\hline Hypertension & $5,007(38.1)$ & $2,862(34.9)$ & \\
\hline Dyslipidaemia & $759(5.8)$ & $623(7.6)$ & \\
\hline $\begin{array}{l}\text { Hypertension and } \\
\text { dyslipidaemia }\end{array}$ & $5,975(45.5)$ & $3,586(43.8)$ & \\
\hline None & $1,405(10.7)$ & $1,119(13.7)$ & \\
\hline $\begin{array}{l}\text { Treatment modality } \\
(n=21,106)\end{array}$ & & & $<0.001^{+}$ \\
\hline Diet and exercise & 245 (1.9) & $15(0.2)$ & \\
\hline $\begin{array}{l}\text { Oral antidiabetic } \\
\text { agents only }\end{array}$ & $11,893(91.6)$ & $6,220(76.6)$ & \\
\hline Insulin only & $312(2.4)$ & $483(6.0)$ & \\
\hline $\begin{array}{l}\text { Oral antidiabetic } \\
\text { agents and insulin }\end{array}$ & $539(4.1)$ & $1,399(17.2)$ & \\
\hline
\end{tabular}

*Analysis performed using Pearson's chi-square test. †statistically significant. T2DM: type 2 diabetes mellitus

augmented by the presence of diabetes mellitus, dyslipidaemia and advanced age. ${ }^{(38,39)}$ However, to achieve target control for cardiovascular disease risk factors, it is important that treating physicians exercise sound clinical judgement to ensure that older patients' safety and quality of life are not negatively affected.

In the present study, the presence of comorbidities hypertension and hypertension plus dyslipidaemia) was less likely to be associated with poor glycaemic control. This finding is similar to that of a Thai study, which showed that patients without hypertension tended to have poorer glycaemic control as compared to those with hypertension; however, the relationship between hypertension/dyslipidaemia and poor glycaemic control was unclear. ${ }^{(13)}$ Furthermore, the finding that the presence of comorbidities was less likely to be associated with poor glycaemic control contradicts the belief that patients with elevated BP and
Table IV. Cardiovascular risk factors associated with glycaemic control.

\begin{tabular}{|c|c|c|c|}
\hline \multirow[t]{2}{*}{ Factor } & \multicolumn{2}{|c|}{ No. (\%) } & \multirow[t]{2}{*}{ p-value* } \\
\hline & $\begin{array}{c}\text { HbA1c } \\
\text { level }<8.0\end{array}$ & $\begin{array}{c}\text { HbA1c } \\
\text { level } \geq 8.0\end{array}$ & \\
\hline $\begin{array}{l}\text { BP }(\mathrm{mmHg}) \\
(\mathrm{n}=21,299)\end{array}$ & & & $0.021^{+}$ \\
\hline$<130 / 80$ & $2,696(20.5)$ & $1,574(19.2)$ & \\
\hline$\geq 130 / 80$ & $10,424(79.5)$ & $6,605(80.8)$ & \\
\hline $\begin{array}{l}\text { Body mass index } \\
(n=21,336)\end{array}$ & & & $0.005^{+}$ \\
\hline Underweight & $272(2.1)$ & $156(1.9)$ & \\
\hline Normal & $2,553(19.4)$ & $1,721(21.0)$ & \\
\hline Pre-obese & $5,342(40.6)$ & $3,372(41.2)$ & \\
\hline Obese & 4,979 (37.9) & $2,941(35.9)$ & \\
\hline $\begin{array}{l}\text { Waist circumference } \\
(n=21,286)\end{array}$ & & & 0.944 \\
\hline Target achieved & $1,793(13.7)$ & $1,113(13.6)$ & \\
\hline Target not achieved & $11,328(86.3)$ & $7,052(86.4)$ & \\
\hline $\begin{array}{l}\text { LDL-C }(\mathrm{mmol} / \mathrm{L}) \\
(\mathrm{n}=17,214)\end{array}$ & & & $<0.001^{+}$ \\
\hline$\leq 2.6$ & $4,019(37.2)$ & $1,854(28.9)$ & \\
\hline$>2.6$ & $6,787(62.8)$ & $4,554(71.1)$ & \\
\hline $\begin{array}{l}\text { HDL-C }(\mathrm{mmol} / \mathrm{L}) \\
(\mathrm{n}=17,392)\end{array}$ & & & $0.001^{+}$ \\
\hline Target achieved & $7,795(71.6)$ & $4,500(69.2)$ & \\
\hline Target not achieved & $3,091(28.4)$ & $2,006(30.8)$ & \\
\hline $\begin{array}{l}\text { Triglyceride }(\mathrm{mmol} / \mathrm{L}) \\
(\mathrm{n}=19,862)\end{array}$ & & & $<0.001^{+}$ \\
\hline$\leq 1.7$ & $7,482(61.0)$ & $3,692(48.6)$ & \\
\hline$>1.7$ & $4,776(39.0)$ & $3,912(51.4)$ & \\
\hline
\end{tabular}

*Analysis was performed using Pearson's chi-square test. ${ }^{\dagger} p$-value is statistically significant. BP: blood pressure; HDL-C: high-density lipoprotein cholesterol; LDL-C: low-density lipoprotein cholesterol; T2DM: type 2 diabetes mellitus

cholesterol have poor glycaemic control. T2DM patients with hypertension and dyslipidaemia could have a greater awareness of their conditions and are thus more aware of the importance of good glycaemic control. Hence, these patients could have adopted healthier lifestyles and been more likely to adhere to their medications. Medication adherence has been shown to be high among patients with comorbid hypertension and hypercholesterolaemia. ${ }^{(40)}$ As the present study did not measure medication adherence, this could have resulted in the observed paradoxical association with glycaemic control.

We found that pre-obesity (BMI 23-27.4 kg/m²) and obesity $\left(\mathrm{BMI} \geq 27.5 \mathrm{~kg} / \mathrm{m}^{2}\right.$ ) were less likely to be associated with poor glycaemic control. Similarly, previous studies have shown that $\mathrm{BMI}$ is not associated with poor glycaemic control. ${ }^{(14,41)}$ In the present study, a smaller proportion of the older T2DM patients with poor glycaemic control was obese as compared to those with good glycaemic control. This could be because T2DM patients with poor glycaemic control tend to have elevated energy expenditure due to the catabolic effect caused by increased protein turnover. ${ }^{(42)}$

We opine that the findings of the present study can be generalised to the majority of older T2DM patients in Malaysia 
Table V. Results of the multiple logistic regression analysis on the factors that predict poor glycaemic control.

\begin{tabular}{|c|c|c|}
\hline \multirow[t]{2}{*}{ Predictor } & \multicolumn{2}{|c|}{ HbA1c level $\geq 8.0 \%$} \\
\hline & $\begin{array}{l}\text { Adjusted OR } \\
(95 \% \mathrm{Cl})\end{array}$ & p-value \\
\hline \multicolumn{3}{|l|}{ Age group (yr) } \\
\hline $60-69$ & $1.96(1.66-2.33)$ & $<0.001^{*}$ \\
\hline $70-79$ & $1.43(1.20-1.71)$ & $<0.001^{*}$ \\
\hline$\geq 80$ & Ref & \\
\hline \multicolumn{3}{|l|}{ Ethnicity } \\
\hline Malay & $1.53(1.41-1.66)$ & $<0.001^{*}$ \\
\hline Indian & $1.32(1.19-1.46)$ & $<0.001^{*}$ \\
\hline Indigenous bumiputera & $1.27(0.84-1.93)$ & 0.261 \\
\hline Chinese & Ref & \\
\hline \multicolumn{3}{|l|}{ T2DM duration (yr) } \\
\hline$<5$ & Ref & \\
\hline $5-10$ & $1.46(1.35-1.58)$ & $<0.001^{*}$ \\
\hline$>10$ & $1.75(1.59-1.91)$ & $<0.001^{*}$ \\
\hline \multicolumn{3}{|l|}{ Comorbidity } \\
\hline Hypertension & $0.71(0.64-0.80)$ & $<0.001^{*}$ \\
\hline Dyslipidaemia & $0.97(0.83-1.13)$ & 0.668 \\
\hline Hypertension and dyslipidaemia & $0.68(0.61-0.75)$ & $<0.001^{*}$ \\
\hline None & Ref & \\
\hline \multicolumn{3}{|l|}{ Treatment modality } \\
\hline Diet and exercise & Ref & \\
\hline Oral antidiabetic agents only & $5.86(3.32-10.34)$ & $<0.001^{*}$ \\
\hline Insulin only & $17.93(9.91-32.43)$ & $<0.001^{*}$ \\
\hline $\begin{array}{l}\text { Oral antidiabetic agents and } \\
\text { insulin }\end{array}$ & $29.42(16.47-52.53)$ & $<0.001^{*}$ \\
\hline \multicolumn{3}{|l|}{ Body mass index } \\
\hline Underweight & $1.04(0.81-1.33)$ & 0.762 \\
\hline Normal & Ref & \\
\hline Pre-obese & $0.89(0.82-0.98)$ & $0.014^{*}$ \\
\hline Obese & $0.76(0.70-0.84)$ & $<0.001^{*}$ \\
\hline \multicolumn{3}{|l|}{ Blood pressure $(\mathrm{mmHg})$} \\
\hline$<130 / 80$ & Ref & \\
\hline$\geq 130 / 80$ & $1.10(1.01-1.20)$ & 0.030 * \\
\hline \multicolumn{3}{|l|}{ LDLC (mmol/L) } \\
\hline$<2.6$ & Ref & \\
\hline$\geq 2.6$ & $1.48(1.38-1.59)$ & $<0.001^{*}$ \\
\hline \multicolumn{3}{|l|}{ Triglyceride (mmol/L) } \\
\hline$\leq 1.7$ & Ref & \\
\hline$>1.7$ & $1.61(1.51-1.73)$ & $<0.001^{*}$ \\
\hline
\end{tabular}

*Statistically significant. Cl: confidence interval; LDL-C: low-density lipoprotein cholesterol; OR: odds ratio; Ref: reference group for comparison in the multiple logistic regression analysis; T2DM: type 2 diabetes mellitus

due to the large sample size. It has been shown that results derived from a study with such a sample size are likely to have the same parameters as a particular population. ${ }^{(43)}$ However, the present study was not without limitations. First, in the ADCM Registry, there was no information regarding the patients' hypoglycaemia status. A comprehensive definition of glycaemic control should include hypoglycaemia status, as it is important in the assessment of older patients. Another limitation was that other modifiable factors that could have contributed to glycaemic control, such as social support, psychological distress and medication adherence, could not be evaluated due to the absence of such information in the registry. Future patient cohort studies that include the hypoglycaemia status of patients and the modifiable factors of glycaemic control are recommended. Finally, due to the nature of data collection in the registry, there were missing values, which may have influenced the results of the present study; thus, these results should be interpreted with caution.

In conclusion, the present study identified several predictors of poor glycaemic control in older patients with T2DM - age $<80$ years, Malay and Indian ethnicities, T2DM duration $\geq 5$ years, the use of oral antidiabetic agents and/or insulin, and BP and lipid levels that do not meet targets. The presence of comorbidities, pre-obesity and obesity were less likely to be associated with poor glycaemic control. We hope that the results of the present study will help to raise awareness of the need for closer monitoring in high-risk groups such as older patients with T2DM.

\section{ACKNOWLEDGEMENTS}

We would like to acknowledge the Director General of the Ministry of Health, Malaysia, for his support and contributions to the registry and the present study. We would like to express our gratitude to the National Clinical Research Centre, Kuala Lumpur, Malaysia, for its support. Our thanks also go out to Dr Murallitharam Munisamy and Dr Nirmala Bhoo Pathy for their contributions in improving this manuscript. The Ministry of Health, Malaysia, supported the present study (NMRR-08-12-1167) and the funder did not have any role in this study or report.

\section{REFERENCES}

1. International Diabetes Federation. Diabetes atlas. 4th ed (updated). Brussels: International Diabetes Federation, 2010.

2. Hogan P, Dall T, Nikolov P. Economic costs of diabetes in the US in 2002. Diabetes Care 2003; 26:917-32.

3. World Health Organization. The World Health Report 2002: reducing risk, promoting healthy lifestyle. Geneva: World Health Organization, 2002.

4. American Diabetes Association. Standards of medical care in diabetes--2012. Diabetes Care 2012; 35 Suppl 1:S11-63.

5. UK Prospective Diabetes Study 33. Intensive blood-glucose control with sulphonylureas or insulin compared with conventional treatment and risk of complications in patients with type 2 diabetes (UKPDS 33). U.K. Prospective Diabetes Study Group. Lancet 1998; 352:837-53.

6. Bi Y, Zhu D, Cheng J, et al. The status of glycemic control: A crosssectional study of outpatients with type 2 diabetes mellitus across primary, secondary, and tertiary hospitals in the Jiangsu province of China. Clin Ther 2010; 32:973-83

7. Ong KL, Cheung BM, Wong LY, et al. Prevalence, treatment, and control of diagnosed diabetes in the U.S. National Health and Nutrition Examination Survey 1999-2004. Ann Epidemiol 2008; 18:222-9.

8. Kemp TM, Barr EL, Zimmet PZ, et al. Glucose, lipid, and blood pressure control in Australian adults with type 2 diabetes: the 1999-2000 AusDiab. Diabetes Care 2005; 28:1490-2.

9. Ezenwaka CE, Offiah NV. Differences in cardiovascular disease risk factors in elderly and younger patients with type 2 diabetes in the West Indies. Singapore Med J 2002; 43:497-503.

10. Mastura I, Chew BH, Lee PY, et al. Control and treatment profiles of 70,889 adult type 2 diabetes mellitus patients in Malaysia - a cross sectional survey in 2009. Int J Collab Res Intern Med Public Health 2011; 3:98-113.

11. Toh MPHS, Wu CX, Leong HSS. Association of younger age with poor glycemic and cholesterol control in Asians with type 2 diabetes mellitus in Singapore. J Endocrinol Metab 2011; 1:27-37.

12. Ng TP, Goh LG, Tan Y, et al. Ethnic differences in glycaemic control in 
adult Type 2 diabetic patients in primary care: a 3-year follow-up study. Diabet Med 2005; 22:1598-604.

13. Thaneerat T, Tangwongchai S, Worakul P. Prevalence of depression, hemoglobin A1C level, and associated factors in outpatients with type-2 diabetes. Asian Biomed 2009; 3:383-90.

14. Benoit S, Fleming R, Philis-Tsimikas A, Ji M. Predictors of glycemic control among patients with Type 2 diabetes: a longitudinal study. BMC Public Health 2005; 5:36.

15. Zhu VJ, Tu W, Marrero DG, Rosenman MB, Overhage JM. Race and medication adherence and glycemic control: findings from an operational health information exchange. AMIA Annu Symp Proc 2011; 2011:1649-57.

16. Hendra TJ, Sinclair AJ. Improving the care of elderly diabetic patients: the final report of the St Vincent Joint Task Force for Diabetes. Age Ageing 1997; 26:3-6.

17. Department of Statistics. Population distribution and basic demographic characteristic of Malaysia - Report 2010. Putrajaya: Department of Statistics, 2010.

18. Franklin SS, Larson MG, Khan SA, et al. Does the relation of blood pressure to coronary heart disease risk change with aging? The Framingham Heart Study. Circulation 2001; 103:1245-9.

19. Wild S, Roglic G, Green A, Sicree R, King H. Global prevalence of diabetes: estimates for the year 2000 and projections for 2030. Diabetes Care 2004 27:1047-53.

20. Shaw JE, Sicree RA, Zimmet PZ. Global estimates of the prevalence of diabetes for 2010 and 2030. Diabetes Res Clin Pract 2010; 87:4-14.

21. Institute for Public Health. The Third National Health and Morbidity Survey (NMHS III) 2006, Diabetes. Malaysia: Ministry of Health Malaysia, 2008.

22. Zhang P, Zhang X, Brown J, et al. Global healthcare expenditure on diabetes for 2010 and 2030. Diabetes Res Clin Pract 2010; 87:293-301.

23. Mafauzy M. Diabetes control and complications in private primary healthcare in Malaysia. Med J Malaysia 2005; 60:212-7.

24. Lee PY, Cheong AT, Zaiton A, et al. Does ethnicity contribute to the contro of cardiovascular risk factors among patients with type 2 diabetes? Asia Pac J Public Health 2013; 25:316-25.

25. Sazlina SG, Mastura I, Ahmad Z, et al. Control of glycemia and other cardiovascular disease risk factors in older adults with type 2 diabetes mellitus: data from the Adult Diabetes Control and Management. Geriatr Gerontol Int 2014; 14:130-7.

26. Tan MY, Magarey J. Self-care practices of Malaysian adults with diabetes and sub-optimal glycaemic control. Patient Educ Couns 2008; 72:252-67.

27. Mastura I, Zanariah H, Fatanah I, et al. An Audit of Diabetes Control and Management (ADCM). Med J Malaysia 2008; 63 Suppl C:76-7.

28. United Nations. World population ageing: 1950 - 2050. New York:
United Nations Publications, 2002.

29. Ministry of Health. Management of type 2 diabetes. 4th ed. Malaysia: Ministry of Health Malaysia, 2009

30. Ministry of Health. Management of obesity. Malaysia: Ministry of Health, 2004.

31. Helmer DA, Sambamoorthi U, Rajan M, Tseng CL, Pogach LM. Individualized, non-age-based glycemic control in elderly veterans with diabetes. Diabetes Care 2008; 31:728-31.

32. Khoo CM, Sairazi S, Taslim S, et al. Ethnicity modifies the relationships of insulin resistance, inflammation, and adiponectin with obesity in a multiethnic Asian population. Diabetes Care 2011; 34:1120-6.

33. Poh BK Jr, Safiah MY, Tahir A, et al. Physical Activity Pattern and Energy Expenditure of Malaysian Adults: Findings from the Malaysian Adult Nutrition Survey (MANS). Malays J Nutr 2010; 16:13-37.

34. Chiu CJ, Wray LA. Factors predicting glycemic control in middle-aged and older adults with type 2 diabetes. Prev Chronic Dis 2010; 7:A08.

35. U.K. prospective diabetes study 16 . Overview of 6 years' therapy of type II diabetes: a progressive disease. U.K. Prospective Diabetes Study Group. Diabetes 1995; 44:1249-58.

36. Lin CF, Wang CY, Bai CH. Polypharmacy, aging and potential drug-drug interactions in outpatients in Taiwan: a restrospective computerized screening study. Drugs Aging 2011; 28:219-25.

37. Akbar DH, Al-Gamdi AA, Hejazi NA. Poor lipid control in type-2 diabetics with and without ischemic heart disease. Endocrine 2003; 21:217-20.

38. Standl E, Balletshofer B, Dahl B, et al. Predictors of 10-year macrovascular and overall mortality in patients with NIDDM: the Munich General Practitioner Project. Diabetologia 1996; 39:1540-5.

39. Lehto S, Rönnemaa T, Haffner SM, et al. Dyslipidemia and hyperglycemia predict coronary heart disease events in middle-aged patients with NIDDM. Diabetes 1997; 46:1354-9.

40. Briesacher BA, Andrade SE, Fouayzi H, Chan KA. Comparison of drug adherence rates among patients with seven different medical conditions. Pharmacotherapy 2008; 28:437-43.

41. Kellow NJ, Savige GS, Khalil H. Predictors of poor glycaemic control during the initial five years post-diagnosis in rural adults with type 2 diabetes. Aust J Rural Health 2011; 19:267-74.

42. Pi-Sunyer FX. Weight loss in type 2 diabetic patients. Diabetes Care 2005; 28:1526-7.

43. Bujang MA, Ghani PA, Zolkepali NA, et al. A comparison between convenience sampling versus systematic sampling in getting the true parameter in a population: Explore from a clinical database: The Audit Diabetes Control Management (ADCM) registry in 2009. 2012 International Conference on Statistics in Science, Business, and Engineering (ICSSBE) 2012, 1-5 